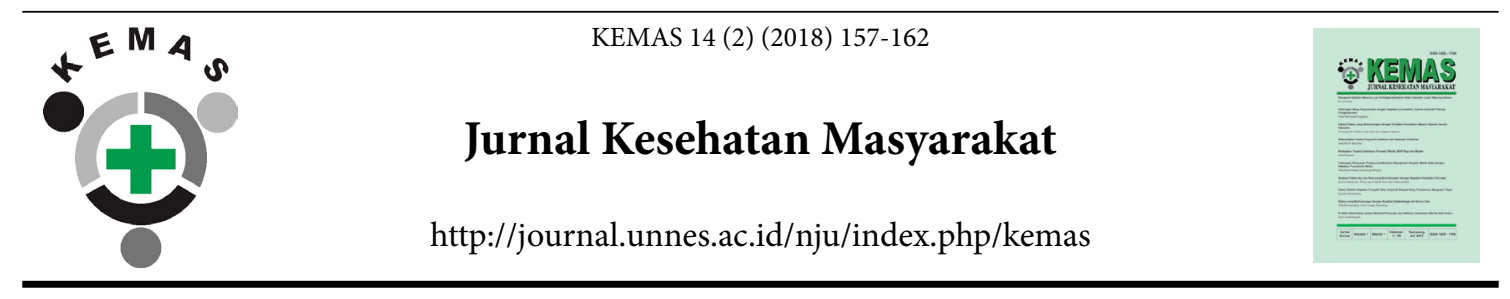

\title{
Children's Safety Education Model through Child-Friendly Games
}

\author{
Evi Widowati ${ }^{1 \bowtie}$, Rulita Hendriyani² ${ }^{2}$ Efa Nugroho ${ }^{1}$, Axel Lee Wye Qin ${ }^{3}$ \\ ${ }^{1}$ Department of Public Health, Universitas Negeri Semarang, Indonesia \\ ${ }^{2}$ Department of Psychology, Universitas Negeri Semarang, Indonesia \\ ${ }^{3}$ Department of Psychology, University Pendidikan Sultan Idris, Malaysia
}

\begin{tabular}{l} 
Article Info \\
\hline Article History: \\
Submitted June 2018 \\
Accepted October 2018 \\
Published November 2018 \\
\hline Keywords: \\
children, game, safety \\
\hline DOI \\
https://doi.org/10.15294/ \\
kemas.v14i2.14705
\end{tabular}

\begin{abstract}
Children are vulnerable to potential hazards from their environment because of their cognitive, psychological and social developments are in immature stages. Formal education is still lacking in teaching safety concepts for children, hence a fun educational media for children is needed so that children can learn through child-friendly educative games. Because of that develop a fun child safety education model is important to improve children's knowledge on the importance of safety, so that children can easily understand how to implement safety values in their life. We used Research and Development (R\&D) level 1 design to develop children's safety education game, which consisted of five stages, started from the data collection up to assess the product effectiveness. The result was a "snake and ladders of safety" game as safety education media for children. We presented 12 pictures in "snake and ladders of safety" game. This research was conducted on year 2017. Based on the game evaluation, the average pretest score was 37.9 and the average posttest score increased to 65.5 , hence there was an increase of knowledge on safety by $72.8 \%$. It can be concluded that this game can increase children's knowledge on safety.
\end{abstract}

\section{Introduction}

Safety and accident are two kinds of different circumstances. Safety is always associated with positive conditions, such as joy, happiness, and prosperity. Accidents have negative connotations, such as sadness, sorrow, and suffering (Alkon et al., 2016). Nevertheless, both always go hand in hand even in coincidence and this is often less likely realized by humans. Changes that occur between these two different circumstances also occur so quickly when humans are falling asleep. Accidents can happen anytime, anywhere, to anyone, and in any activity (Jason, De Amicis and Carter, 1978; Mendoza et al., 2010).

Elementary school children fall into vulnerable group category because they are still in growth and development period. In this period, they usually move a lot because of their high strength and energy. In addition, their curiosity about their environment is also high. Often time, when children play or do their activities, minor or major accident may occur. Most of this may even occur in school, hence the teacher is the one responsible when the accident occurs to students at school (Rizky, 2012). From this situation, teachers have an important role to prevent accidents in children, especially through education of safety behavior in children. In school, students are usually more conditioned emotionally, socially or culturally. The introduction of safety culture

\footnotetext{
Correspondence Address:

Department of Public Health, Universitas Negeri Semarang.

Email : eviwidowati@mail.unnes.ac.id
}

pISSN 1858-1196

eISSN 2355-3596 
can be conducted through simple ways, such as providing safety guidance within weekly assemblies on how to safely walk, cross, cycle, exercise, drive and what to do in emergency situations such as fire, earthquake and others (Kuschithawati, Magetsari and Ng, 2007).

The learning of safety or survival can be performed through three channels, for example informal channels at home by parents, non-formal channels in the community by community or government institutions, and formal channels in schools by teachers (BenArieh, McDonell and Attar-Schwartz, 2009).

Central Bureau of Statistics data in 2015 showed that the number of residents aged $0-14$ years amounted to 69.857 .406 or $27.34 \%$. The number of children and adolescents in Indonesia is estimated to reach 70 million or $28 \%$. The data shows that school-aged children is a large group in the community. The number of school-age children in Indonesia is 6.354.625 or $78 \%$.

Facts show that in general, all activities have risks that threaten the safety of self or others. Accidents can occur due to many factors, one of it is the lack of safety knowledge from early education. Lack of safety knowledge can potentially lead to accidents resulting in minor or severe injury, unconsciousness, lifelong disability or even death. In many cases, accidents that occur in children causes many injuries and even death (Dinas Kesehatan Propinsi Jawa Tengah, 2012).

Most primary school children aged 5-13 years old still require supervision from adults; they have a habit of running suddenly and reckless in decision making (Hidayat, 2012). This is supported by a research conducted on Bernadus 02 primary school Semarang. According to data from School Health Program (UKS), the most common child injuries at school are falling from activities such as walking, running out of the bathroom, exercise and running around the school area. Accident data from July 2015 to January 2016 revealed that 9 students sustained injury from falling and 5 have to be brought to hospital due to fracture and sprain caused by slipping, running and falling. The highest number of injured students was from the fourth grade with 5 students (55.55\%), the second was fifth grade with 3 students (33.33\%) and the last was third grade with 1 student (11.11\%) (Hutasoit and Widowati, 2017).

While current formal education curriculum is very heavy in terms of content, child safety education at school is still minimal although teaching child safety could be done through formal education (through teaching materials, learning process in school, and learning facilities) or informal education from extracurricular activities. We felt that a fun safety education media for children is needed through which children can learn in a fun and interactive way through child-friendly educational games (Widowati et al., 2016). Hence, we developed Child Safety Education Model through child-friendly game.

Child friendly games are all forms of games designed to provide an educational experience or learning experience to their players, including traditional and modern games given educational and teaching content (Turgut, Yaman and Turgut, 2016). Childfriendly games can also mean a form of activity undertaken to derive pleasure from the way or educational media used in play activities, whether consciously or not, having educational content that can be useful in developing selflearners (Springer and Misurell, 2010).

We aimed to develop a fun child safety education model through a child-friendly game to improve children's knowledge on the importance of safety, so that children can easily understand how to implement safety values in their life. Through this game, children would be able to recognize any potential hazards around them and to take the right precautions for it. This can reduce the risk of the accidents. In the long run, it can support the development of national safety culture.

\section{Method}

We used Research and Development (R\&D) design until the fifth stage. This study consisted of five stages: the first stage was basic research and information collection through literature study and observation to identify potential hazards that were often found in children, as well as identify the type of games that have a potential to be developed. The second stage, "develop preliminary form of model" was the development of initial design 
models and game content. The third stage was model trial that was testing the product draft to a few primary school children from grade 1 to grade 6 as sample. The fourth stage was the main model revision in the form of design improvement obtained from the assessment and input from children during the testing phase. The fifth stage was assessment of product effectiveness, conducted in one of the leading private primary schools in Semarang City, Central Java Province, Indonesia.

We collected data through literature study and observation to identify the types of potential hazard affecting children. In addition, we also observed the type of games that have the potential to be developed and often played by Indonesian children. Interviews with a numbers of primary school children were also conducted at the evaluation stage since they are the primary target of the game. Primary school-age children must be exposed to safety education because it can be used as the foundation to build their thinking ability and enrich safety culture in their later life. Children mental, physical, and intelligence development were centered at the age of $0-12$ years. Those years were the golden age of child growth, both physically and psychologically. Therefore, appropriate knowledge in accordance to their proportional age is essential.

This research was tested on 1 class in a private elementary school in Semarang City, Indonesia. The class chosen was grade 3 and the total sample of 28 students. The sample technique used was purposive sampling, with the criteria: elementary students who were able to read fluently, were able to work in teams, could be mobilized well to perform certain game activities and get approval from the school management.

The data collected will be analyzed and utilized as inputs to develop child-friendly safety education models. The assessment of product effectiveness was conducted through pre test and post test results.

\section{Results and Discussion}

Through observations and interviews, it could be inferred that the child-friendly game that have potential to be developed was "snake and ladders game" because it was cheap and liked by most Indonesian children. We increased the value of this game to become a "snake and ladder of safety" game. This game came with detailed instruction and designed to have 12 types of potential hazard pictures that were easily recognized by children. The potential hazards were as follows:

1. Electricity: presented as a child playing with electric socket; 2. Flame: presented as a child playing with stove fire; 3. Tools/machines/ equipments: presented as a child playing with water dispenser; 4 . Motor vehicles: presented as safety behavior while waiting for public transport/bus; 5. Sharp tools/equipments: presented as safety behavior while interacting with knife; 6 . Sharp objects: presented as safety behavior while broken glass were scattered; 7. Animal: presented as the danger of snake venomous bite to a child while playing at the backyard; 8 . Environment: presented as a child running on wet stairs; 9 . Chemical: presented as a child playing with chemical liquid; 10 . Radiation: presented as a child watching television at unsafe distance; 11. Dangerous game: presented as a child playing with dangerous gun with hard pellet; 12. Disaster: presented as safety behavior while dealing with small fire.

"Snakes and ladders of safety" had a total of 12 pictures consisting of: 4 pictures for positive/safety behavior and 8 pictures for negative/dangerous behavior. The details were as follows: negative/dangerous behavior pictures, consist of: playing with stove fire, running while descending a stair, shooting friend with hard pellet gun, touching electric socket using wet hands, playing with chemical liquid, playing in backyard bush while there was a snake watching them, playing with hot water from dispenser, and atching television from unsafe distance. Beside that the positive/safety behavior picture, consist of: sweeping broken glass and plate with footwear and appropriate equipment, extinguishing fire with Light Fire Extinguisher, putting knife in its seath, and waiting for bus in the shelter provided by government.

Examples of dangerous behaviors were presented twice as many as examples of safe behavior so that children can easily remember and quickly understand which dangerous behaviors should be avoided as it may endanger 


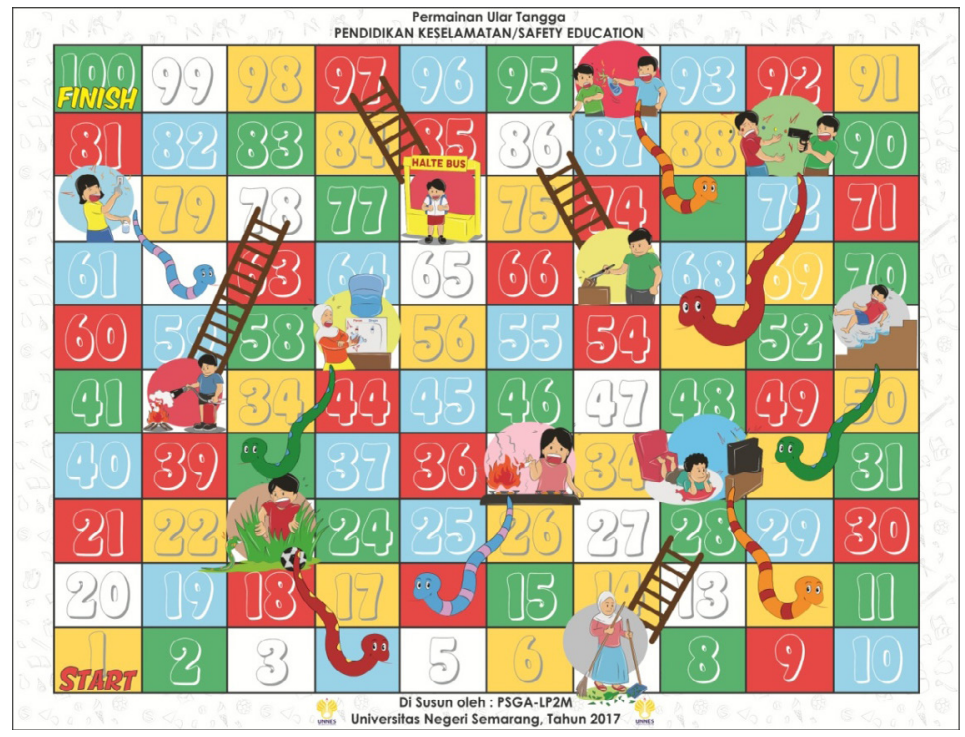

Figure 1. "Snakes and Ladders of Safety" Game.

their own safety and environment.

After the product draft was completed, the product was tested on a sample of $1^{\text {st }}$ to $6^{\text {th }}$ grade primary school children to see whether the game was reasonably operational, easy enough and fun to play, and also to observe child's response while playing the game. Trial was conducted to obtain suggestions to improve product draft.

After the game improvement process was conducted, the next step was testing game effectiveness in a larger group that was at school. The effectiveness test was conducted as follows: before the children play the game, they were asked to do pretest to understand their prior knowledge about the concept of safety. After a pretest, children were invited to play and discuss together through this educational "snakes and ladders ofsafety"game. Through the game, children were asked to explain each content of the pictures and expressed their opinion whether the picture presented was a safe act or not. After playing and discussion was done, children were asked to answer posttest questions, to see whether the game improved their knowledge (Wijaya et al., 2014).

The effectiveness of this game can be seen from the results of pretest-post test. The average pretest score was 37.9 while the post test score was 65.5. Hence, it can be concluded that this game increased children's knowledge by $72.8 \%$. In addition, we observed an increase in enthusiasm and activeness of all parties involved in this activity, namely: children, teachers and school management.

An effective educational media was a health promotion medium that can influence a person's interest, while continuously improving his knowledge (Widowati, Koesyanto and Sugiharto, 2018). A health education media should convey information in hope that users wouldbe influenced and gain knowledge from it. According to Macpherson et al., (2010), respondents who had sufficient knowledge in safety education will have a better ability to identify places or objects that may pose potential hazard to themselves and that poorer children are at increased risk of playground injuries. The objective of this study was to determine the association between playground injury and school socioeconomic status before and after the upgrading of playground equipment to meet CSA guidelines. Injury data were collected from January 1998-December 1999 and January 2004 - June 2007 for 374 elementary schools in Toronto, Canada. The objective of this study was to investigate the effect of a program of playground assessment, upgrading, and replacement on school injury rates and socio-economic status. Injury rates were calculated for all injuries, injuries that did not occur on equipment, and injuries on play equipment. Poisson regression was performed to determine the relationship between injury 
rates and school socio-economic status. Prior to upgrading the equipment there was a significant relationship between socio-economic status and equipment-related injuries with children at poorer schools being at increased risk (Relative risk: 1.52 [95\% CI = 1.24-1.86].

Every human being has different levels of knowledge. The level of knowledge starts from knowing, comprehension, application, analysis, synthesis and evaluation. The higher the level of a person's knowledge, the higher the ability of the individual in assessing material or object as a basis for their action. Factors affecting level of knowledge are education, age, environment and socio-cultural. The higher the level ofeducation, age, and social status of a person mean higher level of knowledge. In addition, there is a relationship between the level of knowledge and behavior. Children who have better knowledge will have a tendency for a better behavior (Diaz-Quijano et al., 2018) attitudes and practices (KAPs).

Education by undergoing training process, the target will gain learning experiences that ultimately lead to improvements in their behavior. Education is a structured facility provided by an organization to study about works related to the knowledge, skills, and behavior of the students. Not everyone can follow and education because education have certain requirements. The purpose of education is to make students more skilled in carrying out their duties and avoid potential dangers that exist around them (Raharjo et al., 2016).

\section{Conclusion}

We conclude that"Snakes and ladders of safety"game provides 12 thematic pictures that consists of 4 pictures of positive/safety behavior and 8 pictures of negative/dangerous behavior.

Pictures presented in this game contain fundamental and important educational values for children. Through child-friendly educational game, children could identify potential safety hazards in their environment. The game is expected to help children understand easily and quickly what behaviors they should avoid and do to maintain the safety of themselves and the environments, and in the end prevent them from any potential injury.

The average of pretest score was (37.9) and posttest score was (65.5), we can infer that the game provided positive contribution in safety knowledge of children by $72.8 \%$.

Competency improvement can be reached by training or enrichment on the existing materials to internalize safety culture in all students as early as possible. Moreover teacher competency in applied science of safety must be enhanced. Because of that schools should be able to integrate safety education in every teaching material, especially in thematic lectures, laboratory and field activities related lectures, or on local material contents and the teacher competence itself. In addition, teachers and school management can use this child-friendly educational game media to fill children's after-school free time and integrate it with various extracurricular activities so as to synergize positively in improving children's safety knowledge. Increasing knowledge using various methods is very important given including to children, because there is a significant correlation between knowledge and attitude, knowledge with activities and attitudes with activities.

\section{Reference}

Alkon, A.D., Rose, R., \& Aronson, S.S., 2016. Health and Safety Checklist for Early Care and Education Programs to Assess Key National Health and Safety Standards. Maternal and Child Health Journal, 20(1), pp.114-127.

Ben-Arieh, A., McDonell, J., \& Attar-Schwartz, S., 2009. Safety and Home-School Relations as Indicators of Children Well Being: Whose Perspective Counts?. Social Indicators Research, 90(3), pp.339-349.

Diaz-Quijano, F.A., Martínez-Vega, R.A., RodriguezMorales, A.J., Rojas-Calero, R.A., LunaGonzález, M.L., \& Díaz-Quijano, R.G., 2018. Association between the Level of Education and Knowledge, Attitudes and Practices Regarding Dengue in the Caribbean Region of Colombia. BMC Public Health, 18(1), pp.143.

Dinas Kesehatan Propinsi Jawa Tengah., 2012. Buku Profil Kesehatan Provinsi Jawa Tengah Tahun 2012, pp.1-118.

Hidayat, E., 2012. Arteri Primer Yang Masuk Wilayah Perkotaan (Evaluation of Typical School Safety Zone on the Primary Arteries Road in Urban Areas). Jurnal Jalan Jembatan, 26(1), pp.45-47.

Hutasoit, F.E., \& Widowati, E., 2017. Gambaran Penerapan Safety Education (Pendidikan 
Keselamatan) di Sekolah Dasar. Journal of Health Education, 2(1), pp.39-46.

Jason, L.A., De Amicis, L., \& Carter, B., 1978. Preventive Intervention Programs for Disadvantaged Children. Community Mental Health Journal, 14(4), pp.272-278.

Kuschithawati, S., Magetsari, R., \& Ng, N., 2007. Faktor Risiko Terjadinya Cedera pada Anak Usia Sekolah Dasar. Berita Kedokteran Masyarakat, 23(3), pp.131-141.

Macpherson, A.K., Jones, J., Rothman, L., Macarthur, C., \& Howard, A.W., 2010. Safety Standards and Socioeconomic Disparities in School Playground Injuries: A Retrospective Cohort Study. BMC Public Health, 10, pp.542.

Mendoza, J.A., Watson, K., Baranowski, T., Nicklas, T.A., Uscanga, D.K., \& Hanfling, M.J., 2010. Validity of Instruments to Assess Students Travel and Pedestrian Safety. BMC Public Health, 10, pp. 257.

Raharjo, B.B., Woro, K.H.O., Nugroho, E., \& Hermawati, B., 2016. Local Potentials as Capital for Planning Nutrition Programs for Urban Fringe Areas in Developing Countries. Pakistan Journal of Nutrition, 15(12).

Rizky, N.A., 2012. Metode Focus Group Discussion dan Simulation Game terhadap Peningkatan Pengetahuan Kesehatan Reproduksi. Jurnal
Kesehatan Masyarakat, Kemas, 8(16), pp.2329.

Springer, C., \& Misurell, J.R., 2010. Game-Based Cognitive-Behavioral Therapy (GB-CBT): An Innovative Group Treatment Program for Children Who Have Been Sexually Abused. Journal of Child \& Adolescent Trauma, 3(3), pp.163-180.

Turgut, T., Yaman, M., \& Turgut, A., 2016. Educating Children on Water Safety for Drowning Prevention. Social Indicators Research, 129(2), pp.787-801.

Widowati, E., Hendriyani, R., \& Nugroho, E., 2016. Development of Child Friendly Educative Game Model as Method to Prevent Violence against Children in School. PSGA Unnes, pp.1-9.

Widowati, E., Koesyanto, H., \& Sugiharto., 2018. Application of Safety Education on Junior High School Teaching Materials. Advance in Health Research, 12, pp.258-262.

Wijaya, I.M.K., Agustini, N.N.M., \& Tisna, D.G., 2014. Pengetahuan, Sikap dan Aktivitas Remaja SMA dalam Kesehatan Reproduksi di Kecamatan Buleleng. Jurnal Kesehatan Masyarakat, Kemas, 10(1), pp.33-42. 